\title{
Assessment of a rail vehicle running with the damaged wheel on a ride comfort for passengers
}

\author{
Ján Dižo ${ }^{1,{ }^{*}}$, Miroslav Blatnický ${ }^{1}$, Stasys Steišūnas ${ }^{2}$, Blanka Skočilasová $^{3}$ \\ ${ }^{1}$ Department of Transport and Handling Machines, Faculty of Mechanical Engineering, University \\ of Žilina, Univerzitná 8215/1, 01026 Žilina, Slovak Republic \\ ${ }^{2}$ Railway Transport Department, Faculty of Transport Engineering, Vilnius Gediminas Technical \\ University, J. Basanavičiaus g. 28, LT-03224 Vilnius, Lithuania \\ ${ }^{3}$ Department of Machines and Mechanics, Faculty of Production Technology and Management, Jan \\ Evangelista Purkyně University, Railway Transport Department, Faculty of Transport Engineering, \\ Vilnius Gediminas Technical University, Na Okraji 1001/7, 40001 Ústí nad Labem, Czech Republic
}

\begin{abstract}
In certain conditions rail vehicles wheels can be during operation damaged. Then, the profile of wheels is no longer circular, but it is changed depending on the type and severity of defects. When such rail vehicle with the damaged wheel operates, the quality of a ride comfort for passenger is degraded. This article is focused on the assessment of ride comfort for passenger based on results obtained from dynamic analyses. Simulations and calculations were carried out in commercial multibody software. In our research we considered one type of the railway wheel untrueness - wheel-flat. This type of wheel damaging is relatively common and has such influence on the ride comfort for passenger worsening, which needs to be detected and investigated.
\end{abstract}

Keywords: rail vehicle, wheel-flat, ride comfort for passenger, computer simulation

\section{Introduction}

The ride comfort is one of the most important rail vehicle assessment standards. The ride comfort is given by several different adverse effects which passengers are subjected. These effects include mainly noise, air humidity, lighting, temperature, ventilation, but mainly vehicle vibrations. Negative vibrations can be caused during running due to track irregularities and also due to the wheel untrueness. One of the most frequently wheel untrueness is the wheel-flat [1]. This type of wheel defect occurs when the wheel locks and slides along the rail for the sake of malfunctioning brakes or because the overmuch braking force in relation to the practicable friction in the wheel/rail contact.

The ride comfort is one of fundamental assumptions of a rail vehicle achievement and popularity for passengers and transport operators. For this reason a big emphasis is given on the rail vehicle analysis before its operation $[2,3]$. For analysis computer simulations and detailed analysis of measured experimental values are widely used.

\footnotetext{
*Corresponding author: jan.dizo@fstroj.uniza.sk

Reviewers: Vladimír Dekýš, Milan Nad’
} 


\section{Passenger ride comfort}

The passenger ride comfort can be evaluated by the so-called indirect method [4-6]. For this method it is necessary to know acceleration values of a rail vehicle in analysed points. Acceleration values are filtered and weighted functions that take into account the human sensitivity to the vibration in reference directions. Such modified values are statistically evaluated subsequently and comfort indices for the floor and the standing and seated person are calculated numerically. Acceleration inputs to the calculation can be obtained by measurement [7-9] or as a result of the simulation calculation [10].

During the rail vehicle running dynamic movements of wagon body arise. These movements effect as vibrations. Passengers are subjected these negative effects during operation [11].

The ride comfort is the total sensation which the rail vehicle body movements generate in the passenger body. These rail vehicle body movements are to the whole passenger body transmitted in passenger - vehicle points $[12,13]$.

These sensations are classified as:

- Average sensation - due to vibrations.

- Immediate sensation - due to the immediate changing of the average sensation by the short effect.

Body accelerations are not only used in order to evaluate the passenger ride comfort but also to evaluate running properties and vehicle vibrations. Whereas comfort criterions are stricter as criterions for vehicle running properties in order to operation approval, there is to the ride comfort optimization concentrated at the rail vehicles dynamic analysis mostly, there through good running properties are achieved.

As mentioned above, rail vehicle body movements are to the human body transmitted through contact points according to the passenger position (Fig. 1) [4]:

- Standing position: floor-feet.

- Seated position: headrest-neck, armrest-arms, seat-hip, backrest-back, floor-feet.

The passenger ride comfort is valuated according to the EN 12299:2009 [4] standard based on the UIC 513. The ISO 2631 standard is also used, eventually the grade quality running $\mathrm{W}_{\mathrm{z}}$ by Sperling. Ride comfort criterions appear from body accelerations measured namely in the vertical, lateral, eventually longitudinal direction.

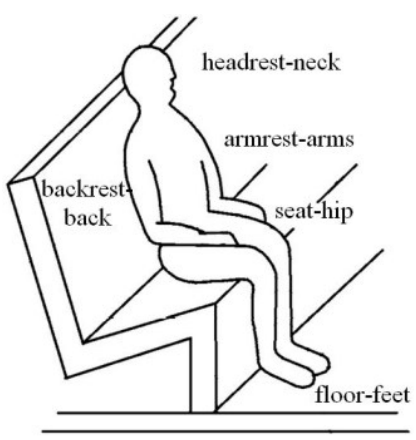

Fig. 1. Interfaces points

For the passenger ride comfort evaluation weighting filters are used which deliberate the human body sensitivity by particular of frequency. These filters are different for vertical and lateral direction. Weighting filters accordance with EN 12299:2009 standard (measurement on the floor) for the lateral direction are consistent to the ISO 2631 filters, they are different for vertical direction a bit only. Compared with the older grade quality 
running $\mathrm{W}_{\mathrm{z}}$ filters for lateral direction are particularly significantly different, therefore the different criterion can reach to different ride comfort quality results in spite of the same vehicle [14].

\subsection{Calculation of ride comfort indices}

The ride comfort indices calculation assumes the measurement of acceleration $\left(\mathrm{m} / \mathrm{s}^{2}\right)$ in the $x, y$, and $z$ direction $\left(a_{x}, a_{y}, a_{z}\right)$. Based on the sampling frequency $f_{n}$ is determined the number of samples that are recorded in the time interval of 5 sec. At the sampling frequency of $200 \mathrm{~Hz}$ during $5 \mathrm{sec}$. are obtained 1000 samples. Based on the condition of samples occurrence in $5 \mathrm{sec}$. intervals shooting time is divided into $5 \mathrm{sec}$. periods. Each of the sections has clearly established the start $T_{l}$ and the end $T_{2}$ in time. For the dataset at the each time interval is performed the fast Fourier transformation (FFT). For range of frequencies $0.4 \mathrm{~Hz}-100 \mathrm{~Hz}$ is performed CAW calculation [4, 6].

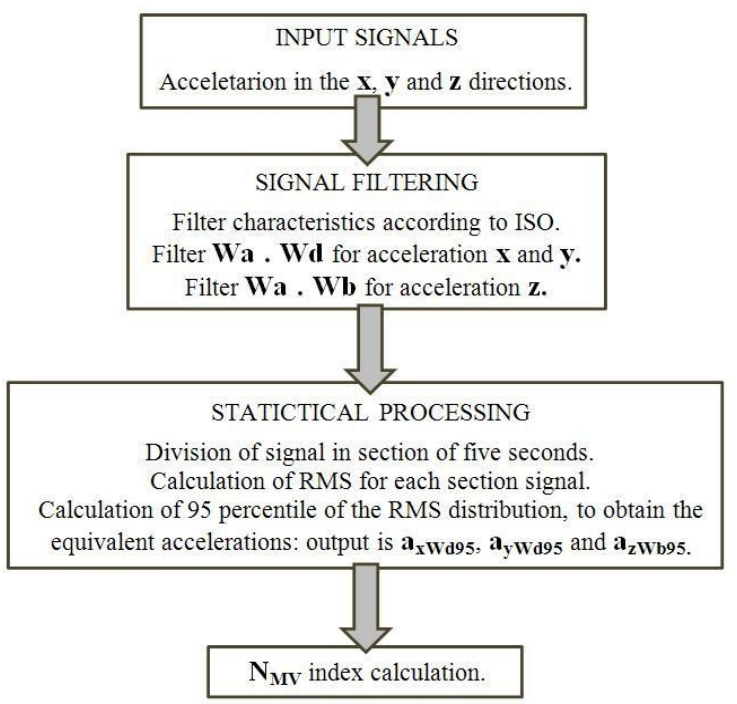

Fig. 2. Workflow for the $\mathrm{N}_{\mathrm{MV}}$ index calculation

The weighting filter $w$, which takes into account the human body sensitivity at different frequencies, is applied depending on the type of evaluation - floor, standing position or seated position.

Weighting function modified acceleration values are statistically evaluated and summation functions in histograms are determined.

The ride comfort calculation procedure is shown in Fig. 2.

Result values of passenger ride comfort indices for the average comfort are calculated as follows [4]:

- Floor:

$$
N_{M V}=6 \cdot \sqrt{\left(a_{X P 95}^{W_{d}}\right)^{2}+\left(a_{Y P 95}^{W_{d}}\right)^{2}+\left(a_{Z P 95}^{W_{b}}\right)^{2}}
$$


It can be sometimes useful depending on the application to calculate partial indices of the ride comfort:

$$
\begin{aligned}
& N_{M V_{x}}=6 . a_{X P 95}^{W_{d}}, \\
& N_{M V_{y}}=6 . a_{Y P 95}^{W_{d}}, \\
& N_{M V_{Z}}=6 . a_{Z P 95}^{W_{b}},
\end{aligned}
$$

- Standing position:

$$
N_{V D}=3 \cdot \sqrt{16 \cdot\left(a_{X P 50}^{W_{d}}\right)^{2}+4 \cdot\left(a_{Y P 50}^{W_{d}}\right)^{2}+\left(a_{Z P 50}^{W_{b}}\right)^{2}}+5 \cdot\left(a_{X P 95}^{W_{d}}\right)^{2}
$$

- Seating position:

$$
N_{V A}=4 \cdot\left(a_{Z P 95}^{W_{b}}\right)^{2}+2 \cdot \sqrt{\left(a_{Y P 95}^{W_{d}}\right)^{2}+\left(a_{Z P 95}^{W_{b}}\right)^{2}}+4 \cdot\left(a_{X D 95}^{W_{c}}\right)^{2}
$$

Analyses in this paper are focused on the $N_{M V}$ index computation. To calculate this comfort index, into the calculation accelerations in longitudinal $(x)$, lateral $(y)$ and vertical (z) direction of each point of interest must input.

\section{Assessment of the passenger ride comfort by means of simulation computations}

In the development and manufacture rail vehicles process is given the care of a test and validation their static and dynamic properties. There is the main emphasis to the effective resources exploitation in a competition, therefore there are preferably used a lot of types of rail vehicle computer simulations $[15,16]$ as a mechanical system, its subsystems and its particular parts [17-20].

Generally there is an experimental process of data obtaining that are needed to optimization of new products designing and creating. The computer simulation is characterized by the real vehicle system replace computer model created especially for the specified conditions.

The dynamic analysis evaluates changes of rail vehicle behaviours as a mechanical system under the influence of equilibrium change.

Dynamic simulations of the mechanical system can be performed by using of a variety tools virtual reality [21-24]. For purposes of the passenger car model creation, dynamic simulation, processing of results and ride comfort for passenger assessment we have used the Simpack/Rail package.

Simpack/Rail allows modelling and analysis of rail vehicles and similar devices of every kind, from trams to high-speed trains but also from material handling systems to roller coasters.

Most parts of a rail vehicle model in Simpack are made of standard Modelling Elements, but contact between the rails and wheels and the track uses specialized Modelling Elements. Calculation of ride comfort indices requires further specialized Control Element (accelerometer) using.

As it is already mentioned above, the passenger ride comfort can be evaluated by the socalled indirect method $[4,6,7]$. 


\subsection{Computer model of the passenger car}

The ride comfort for passenger was evaluated for the passenger car with four wheelsets. All wheelsets had the same profile and there are guided by the swinging arms in bogies. Between wheelsets and bogie frame the primary suspension is mounted and the passenger car body and bogies the secondary suspension system connects. The wagon is equipped with primary and secondary suspensions. Main parts of vehicle are body of wagon, bogie frames, axle boxes and wheelsets.

The Fastsim method was used for the rail/wheel contact calculation. There is the standard method for vehicle dynamics [25-29]. During the wheel/rail contact modelling process the wheel-flat was specified. It comes to this that the nominal radius of a wheel radius varies with the wheel rotation angle. In Simpack the wheel untrueness is possible to model in three ways: radius deviation, Fourier coefficients and harmonic function (simple polygonality) $[2,30]$.

In our research the radius deviation is considered. In this model, radius deviation is prescribed pointwise in polar coordinates by defined input function. Its independent coordinate is the rotation angle, which must be defined in the interval $[0,2 \pi]$ and the radius deviation $\Delta R$ or the actual local radius $R$ in meters are dependent coordinates. The mean value is subtracted from the values to get the actual radius deviation. Complete data are splined to allow a continuous interpolation including the derivatives.

The wheel movement with a flat can be described follow (Fig. 3). The wheel drops for a distance from point $T_{1}$ to $T_{3}$ and it induces an impact on the top of rail in point $B$ [31].

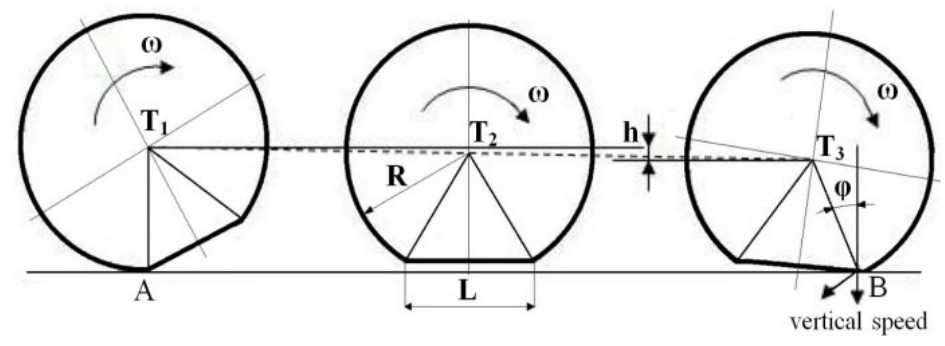

Fig. 3. Wheel/rail impact caused by the wheel-flat [25]

If we assuming that the wheel-flat length $L$ and the wheel radius $R$ are constant, the equation of motion can be derived (7):

$$
\omega \sqrt{\frac{2 . h}{g}}=2 \cdot \arcsin \frac{L}{2 \cdot R}-\arccos \left(1-\frac{h}{R}\right)
$$

where $\omega$ represents the rotation speed, $h$ is the dropping distance of the wheel, $g$ is the gravity acceleration, $L$ and $R$ are the wheel-flat length and the rolling radius of the wheel respectively [31]. The impact on a rail is not only from the wheel dropping but also from the vertical speed component. This cannot be neglected. The wheel rotation speed is considerable and therefore it can induce relatively high vertical impact forces. Its vertical component is expressed as (8):

$$
v_{\text {ver. }}=\omega \cdot R \cdot \sin \varphi
$$

where $\varphi$ marks the angle shown in Fig. 2. It is calculated as [1] (4):

$$
\varphi=\arccos \left(1-\frac{h}{R}\right)
$$


The passenger wagon was run on the straight track section of 5,000 $\mathrm{m}$. The UIC60 rail profile and the S1002 wheel profile were used. The track model contains also measured track irregularities prescribed by discrete form.

For the assessment of the passenger ride comfort is necessary to know accelerations in individual direction $x, y$ and $z$. Therefore specialized Control Elements (167: Accelerometer) were defined into points as Fig. 4 shows.

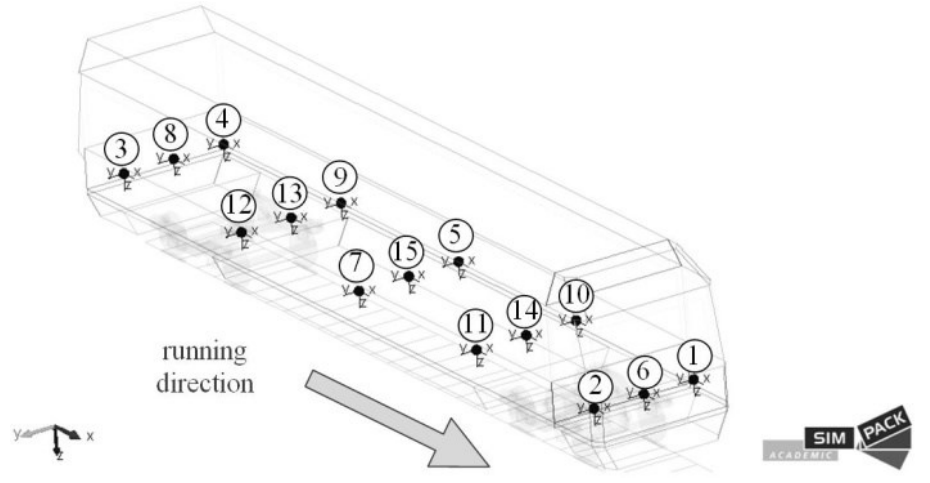

Fig. 4. Location of points for the passenger ride comfort assessment on the wagon floor

The process of the passenger ride comfort index computation at the wagon floor level consists of several steps. Outputs of procedures are frequency weighted RMS-values of acceleration $a_{X P 95}^{W_{d}}, a_{Y P 95}^{W_{d}}$ and $a_{Z P 95}^{W_{b}}$, respectively, where $a$ is RMS-value of acceleration; $X$, $Y$ and $Z$ are directions of acceleration, $P$ is measured position (in our case floor), number 95 represents 95-percentile, $W_{d}$ is weighting curve in $x$ and $y$ direction at the floor level and $W_{b}$ is weighting curve for $z$ direction at the floor level.

The five-second RMS-values of the frequency weighted accelerations are calculated as:

$$
\begin{aligned}
& a_{x j}^{W_{d}}(t)=\left[\frac{1}{\tau} \cdot \int_{t-\tau}^{t}\left(\ddot{x}_{W_{d}}^{*}(\tau)\right)^{2} d \tau\right]^{0.5} \\
& a_{y j}^{W_{d}}(t)=\left[\frac{1}{\tau} \cdot \int_{t-\tau}^{t}\left(\ddot{y}_{W_{d}}^{*}(\tau)\right)^{2} d \tau\right]^{0.5} \\
& a_{z j}^{W_{d}}(t)=\left[\frac{1}{\tau} \cdot \int_{t-\tau}^{t}\left(\ddot{z}_{W_{d}}^{*}(\tau)\right)^{2} d \tau\right]^{0.5}
\end{aligned}
$$

From values of frequency weighted acceleration, the NMV indices for all points according to the equation (1) were calculated. The evaluation of the passenger ride comfort based on the estimated comfort indices and comparing with the scale in Tab. 1.

Table 1. Comfort index evaluation scale [4]

\begin{tabular}{|c|c|}
\hline $\mathbf{N}_{\mathbf{M V}}<\mathbf{1 . 5}$ & Very comfortable \\
\hline $\mathbf{1 . 5} \leq \mathrm{N}_{\mathbf{M V}}<\mathbf{2 . 5}$ & Comfortable \\
\hline $\mathbf{2 . 5} \leq \mathrm{N}_{\mathbf{M V}}<\mathbf{3 . 5}$ & Medium \\
\hline $\mathbf{3 . 5} \leq \mathrm{N}_{\mathbf{M V}}<\mathbf{4 . 5}$ & Uncomfortable \\
\hline $\mathrm{N}_{\mathbf{M V}}>\mathbf{4 . 5}$ & Very uncomfortable \\
\hline
\end{tabular}


For the assessment of negative effects of the passenger car running with the wheel-flat on the passenger ride comfort, the wagon was run at various speeds. We have chosen the speed interval from $30 \mathrm{~km} / \mathrm{h}$ up to $210 \mathrm{~km} / \mathrm{h}$ with the step of $30 \mathrm{~km} / \mathrm{h}$. Thus, in the aggregate there were performed seven simulations and for a comparison other seven simulations with the passenger car with a purely wheel radius (without wheel-flat). The ride comfort indices were calculated for both cases. Results of all analyses are shown in Figs. 5 - 11.

Calculated indices of the passenger ride comfort allow objectify expected subjective discomfort during travelling.

Generally, from all results we can see that the position in which the passenger experiences the least influence of acceleration on the body is near to the centre of the wagon body (centre of gravity). Areas, in which the highest values of acceleration are generated, are in the front and rear sectors of the passenger car.

Let's us now focus on how the passenger car running with the wheel-flat influences on the ride comfort at various speeds. All figures are arranged so that results from analyses with the wheel-flat are on the right side and results from analyses without the wheel-flat are on the left side (take note of Figures).

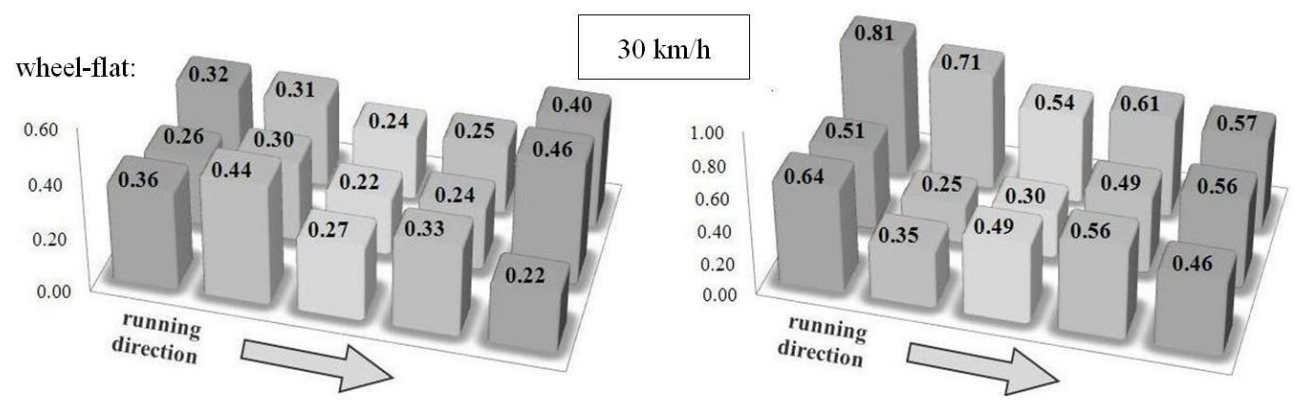

Fig. 5. The $N_{M V}$ indices for the speed of $30 \mathrm{~km} / \mathrm{h}$ with wheel-flat (left) and without wheel-flat (right)

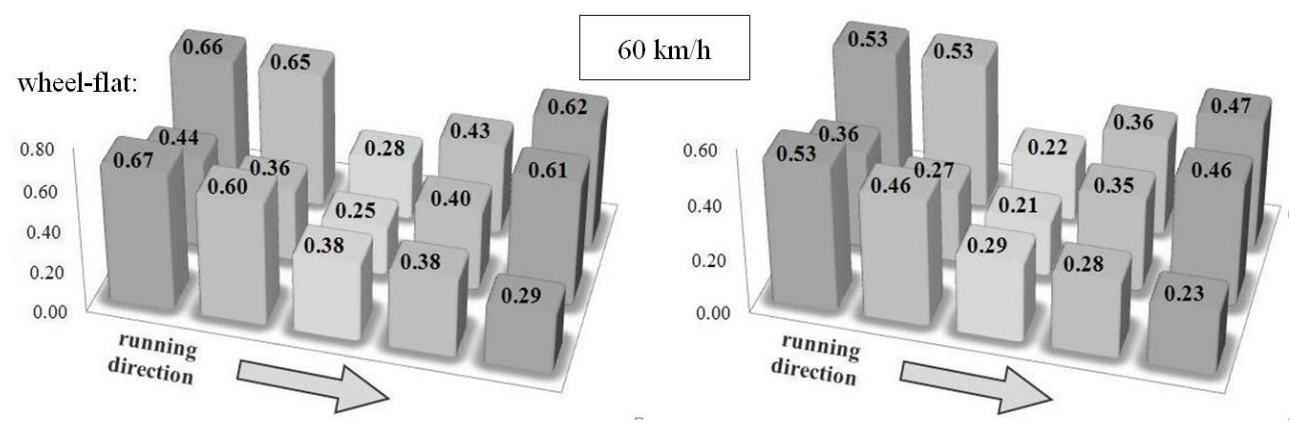

Fig. 6. The $N_{M V}$ indices for the speed of $60 \mathrm{~km} / \mathrm{h}$ with wheel-flat (left) and without wheel-flat (right) 


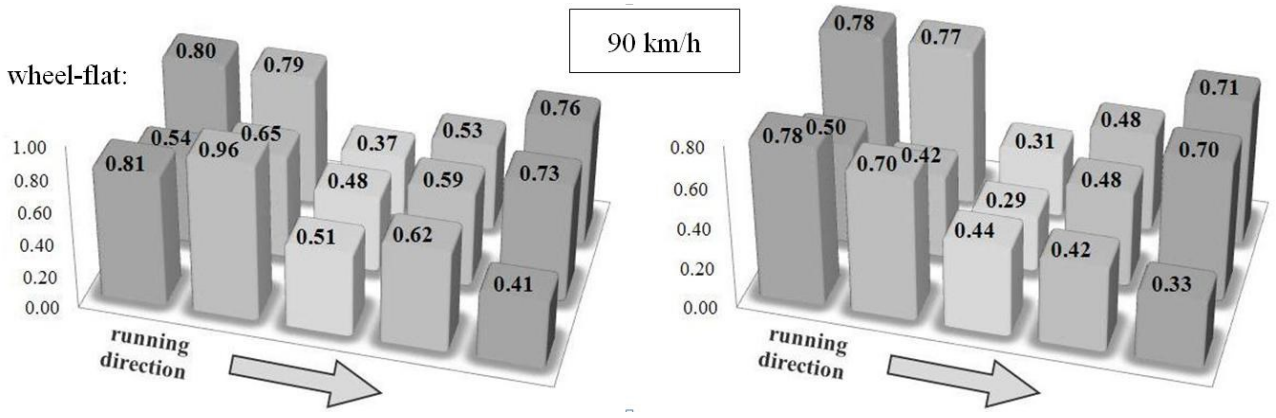

Fig. 7. The $N_{M V}$ indices for the speed of $90 \mathrm{~km} / \mathrm{h}$ with wheel-flat (left) and without wheel-flat (right)
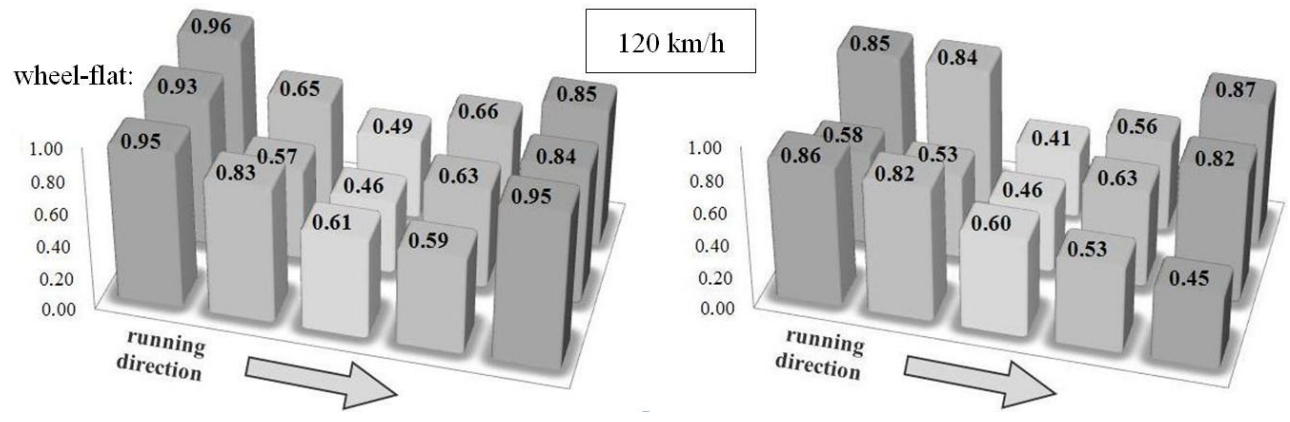

Fig. 8. The $N_{M V}$ indices for the speed of $120 \mathrm{~km} / \mathrm{h}$ with wheel-flat (left) and without wheel-flat (right)
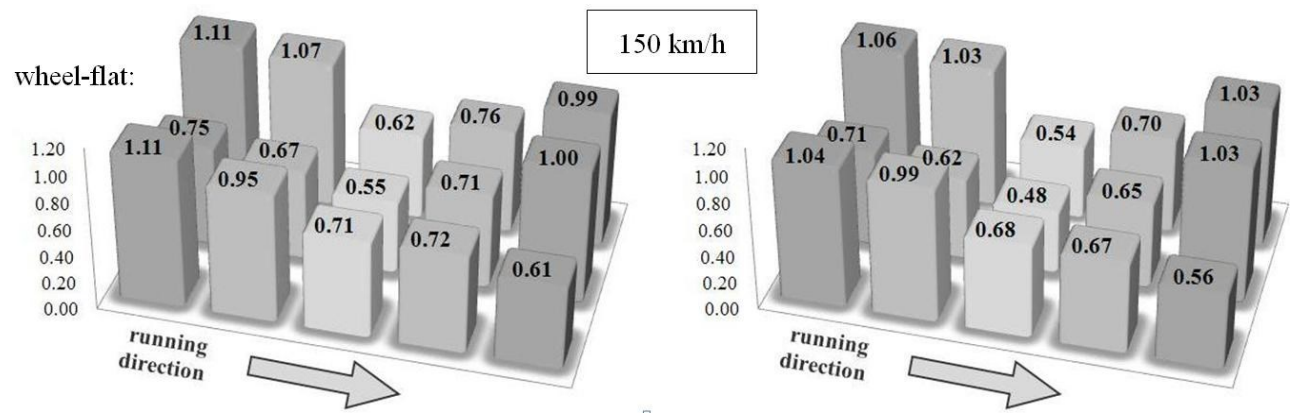

Fig. 9. The $N_{M V}$ indices for the speed of $150 \mathrm{~km} / \mathrm{h}$ with wheel-flat (left) and without wheel-flat (right)

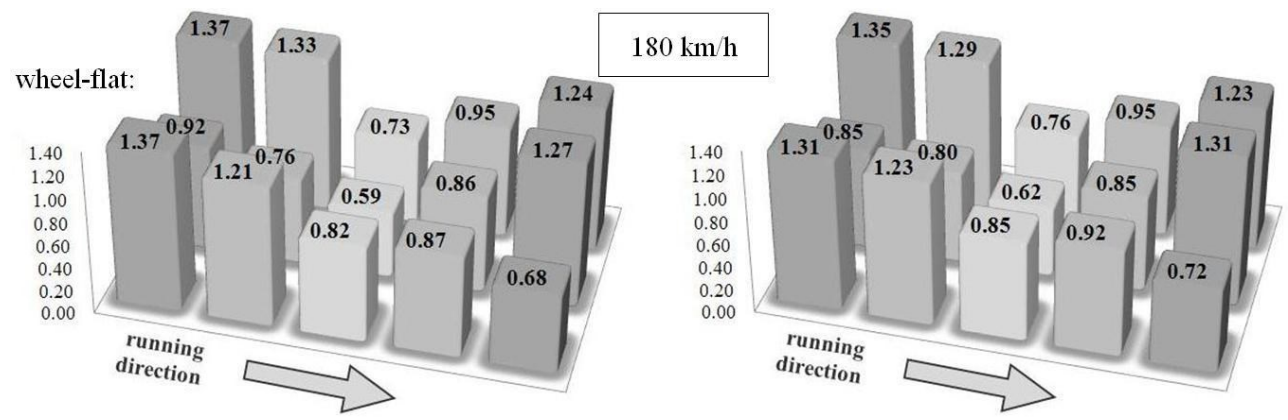

Fig. 10. The $N_{M V}$ indices for the speed of $180 \mathrm{~km} / \mathrm{h}$ with wheel-flat (left) and without wheel-flat (right) 


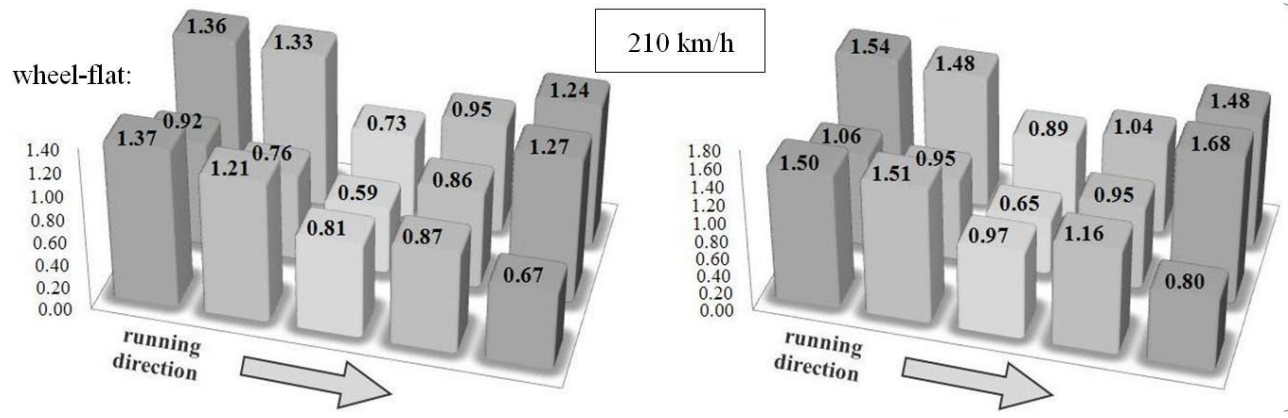

Fig. 11. The $N_{M V}$ indices for the speed of $210 \mathrm{~km} / \mathrm{h}$ with wheel-flat (left) and without wheel-flat (right)

Comparison calculated ride comfort index $N_{M V}$ shown in Figs. 5 - 11 stepwise form $30 \mathrm{~km} / \mathrm{h}$ (Fig. 5) up to $210 \mathrm{~km} / \mathrm{h}$ we can see, as we are expected, that ride comfort for passenger is worse in case passenger car running with wheel-flat. But except for two investigated cases: if the wagon runs at the relatively low speed of $30 \mathrm{~km} / \mathrm{h}$ and at the highest analysed speed of $210 \mathrm{~km} / \mathrm{h}$.

For these two cases we have identified that after performing the entire calculating procedure of the $\mathrm{N}_{\mathrm{MV}}$ indices, that the wagon running if less comfortable in wagon without wheel-flat. This is an interesting detection primarily concerning the low speed because in published works $[30,32]$ there is found out such phenomenon, that exceedingly the driving a rail vehicle with damaged wheel at lower speed has more negative effects. Together herewith there is necessary to warn that in referred publications negative impacts from the track point of view were investigated but not from the passenger ride comfort point of view.

Finally, from the global view and comparison all calculated $\mathrm{N}_{\mathrm{MV}}$ indices values with the scale given in EN 12299:2009 [4] (Tab. 1), the travelling in the analysed passenger car is classified for as „,very comfortable“ $\left(N_{M V}<1.5\right)$ except of the case, when the wagon without the wheel-flat run at the speed of $210 \mathrm{~km} / \mathrm{h}$, where one point (Point 6) in front of wagon body and three points (Points 3, 4 and 12) in the rear part of the wagon body are classified as ,comfortable“ (values of the $N_{M V}$ ride comfort index exceeded 1.5).

In our future research we will focus on the more detailed investigation and comparison of the wagon running at the specific speeds and we will perform more simulations with smaller step of the running speed in order to detect, which the wagon with the damaged wheel generates most adverse effects on passengers at.

\section{Conclusion}

The passenger ride comfort is the criterion, whose assessment is the most actual today. The ride comfort is mainly from acceleration signals assessed. The EN, UIC and ISO standards states conditions, which assessment is performed. Signals are obtained by measuring accelerations at various wagon body points.

When neither the real vehicle nor measured acceleration data are available computer simulation tools allow obtaining these acceleration data. Through them we can perform computer simulations of a modelled rail vehicle on a track for various excitement values and assess vehicle properties based on prescribed parameters. Then, consistent with valid standards we can calculate indices of ride comfort for passengers based on results of dynamic model of the analysed vehicle. 
This article was supported by the project VEGA 1/0927/15 "Research of the use of alternative fuels and hybrid drives on traction vehicles with aim to reduce fuel consumption and air pollutants production".

The work was supported by the Cultural and Educational Grant Agency of the Ministry of Education of the Slovak Republic in project No. KEGA 077ŽU-4/2017: Modernization of the Vehicles and engines study program.

This publication is the result of the project implementation: Modern methods of teaching control and diagnostic systems of engine vehicles ITMS 26110230107 supported by the Operational Programme Education funded by the ESF.

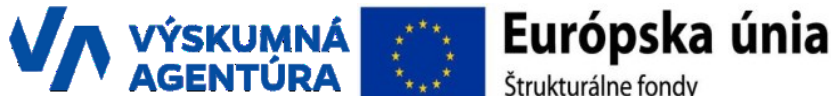

\section{References}

1. M. Bogdevicius, R. Zygiene, G. Bureika, S. Dalydka, An analytical mathematical method for calculation of the dynamic wheel-rail impact force caused by wheel flat. Vehicle System Dynamics 5, 689-705 (2016)

2. J. Dižo, S. Steišūnas, M. Blatnický, Dynamic analysis of motion smoothness of rail vehicle with wheel-flat. Proceedings of $22^{\text {nd }}$ International conference "Current problems in rail vehicles - PRORAIL 2015" I 22, 83-92 (2015)

3. J. Galliková, R. Poprocký, P. Volna, Implementation of FMEA method in maintenance of semi-trailer combination. Diagnostyka 4, 85-92 (2016)

4. EN 12299:2009, Railway Applications - Ride Comfort for Passengers - Measurement and Evaluation. European Committee for Standardization, Brussels (2009)

5. J. Gerlici, Comfort for passenger of rail vehicle assessment. Advanced methods in computational and experimental mechanics, 141-172 (2013)

6. Z. Ondrová, J. Gerlici, T. Lack, Comfort for passengers of railway vehicle analysis. Proceedings of $7^{\text {th }}$ European conference of young research and science workers "TRANSCOM 2007" 7, 205-210 (2007)

7. J. Gerlici, T. Lack, J. Harušinec, Realistic simulation of railway operation on the RAILBCOT test stand. Applied mechanics and materials 486, 387-395 (2014)

8. J. Gerlici, M. Gorbunov, K. Kravchenko, A. Kostyukevich, O. Nozhenko, T. Lack, Experimental Rigs for Wheel/Rail Contact research. Manufacturing Technology 5, 909-916 (2016)

9. J. Gerlici, T. Lack, Rail vehicles brake components test bench utilisation. Applied mechanics and materials 486, 379-386 (2014)

10. S. Dailydka, S. Naimovičius, V. Lingaitis, Analysis of passenger vibration comfort in a train. Transport Means - Proceedings of the International Conference, International Conference Transport Means 2012, Kaunas, Lithuania 16, 302-305 (2012)

11. V. Hauser, O. Nozhenko, K. Kravchenko, M. Loulová, J. Gerlici, T. Lack, Impact of three axle boxes bogie to the tram behavior when passing curved track. Procedia Engineering 192, 295-300 (2017)

12. T. Lack, J. Gerlici, Vehicles Dynamical Properties Analysis from the Point of View of Comfort for Passengers. Archives of Transport 1-2, 91-110. (2007)

13. T. Lack, J. Gerlici, Analysis of Vehicles Dynamic Properties from the Point of View of Passenger Comfort. Komunikacie 2, 10-18 (2008) 
14. M. Maňurová, A. Suchánek, The analysis of a rail vehicle with a tilting bogie. Manufacturing Technology 5, 1020-1027 (2016)

15. P. Št’astniak, J. Harušinec, Computer aided simulation analysis for computation of modal analysis of the freight wagon. Komunikacie 4, 73-79 (2013)

16. M. Kostrzewski, R. Mełnik, Numerical dynamics study of a rail vehicle with differential gears. Procedia Engineering 192, 439-444 (2017)

17. P. Hejma, M. Svoboda, J. Kampo, J. Soukup, Analytic Analysis of a Cam Mechanism. Procedia Engineering 177, 3-10 (2017)

18. F. Klimenda, J. Soukup, Modal analysis of thin aluminium plate. Procedia Engineering 177, 11-16 (2017)

19. P. Baran, M. Brezáni, P. Kukuča, P. Št’astniak, Basic dynamical analysis and comparison of balancing systems of non-conventional piston machine FIK. Procedia Engineering 192, 34-39 (2017)

20. V. Baniari, M. Blatnická, M. Šajgalík, M. Vaško, M. Sága, Measurement and numerical analyses of residual stress distribution near weld joint. Procedia Engineering 192, 22-27 (2017)

21. A. Sapietová, J. Bukovan, M. Sapieta, L. Jakubovičová, Analysis and implementation of input load effects on an air compressor piston in MSC.ADAMS. Procedia Engineering 177, 554-561 (2017)

22. A. Sapietová, L. Gajdoš, V. Dekýš, M. Sapieta, Analysis of the influence of input function contact parameters of the impact force process in the MSC.ADAMS. Advanced mechatronics solutions 393, 243-253 (2015)

23. R. Labuda, D. Barta, A. Kovalčík, Effective use of the braking effect of vehicle drivetrain at deceleration. Proceedings of XLI. International scientific conference of Czech and Slovak university departments and institutions dealing with the research of internal combustion engines "KOKA 2010" 41, 206-211 (2010)

24. P. Kopas, L. Jakubovičová, M. Vaško, M. Handrik, Fatigue resistance of reinforcing steel bars. Procedia Engineering 136, 193-197 (2016)

25. J. Gerlici, T. Lack, Modified HHT method for vehicle vibration analysis in time domain utilisation. Applied mechanics and materials 486, 396-405 (2014)

26. Gerlici, T. Lack, Contact geometry influence on the rail/wheel surface stress distribution. Procedia Engineering 1, 2249-2257 (2010)

27. J. Gerlici, T. Lack, Railway wheel and rail head profiles development based on the geometric characteristics shapes. Wear 1-2, 246-258 (2011).

28. T. Lack, J.Gerlici, A modified strip method to speed up the calculation of tangential stress between wheel and rail. Applied mechanics and materials 486, 371-378 (2014)

29. T. Lack, J. Gerlici, A modified strip method to speed up the calculation of normal stress between wheel and rail. Applied mechanics and materials 486, 359-370 (2014)

30. J. Dižo, S. Steišūnas, M. Blatnický, Simulation Analysis of the Effects of a rail Vehicle Running with Wheel Flat. Manufacturing Technology 5, 889-896 (2016)

31. J. Bian, G. Yuantong, M.H. Murray, A Dynamic wheel-rail impact analysis of railway track under wheel flat by finite element analysis. Vehicle System Dynamics 6, 784-797 (2013)

32. M. Pawełczyk, P. Lesiak, R. Podsiadło, Simulation study of the 4-axle wagon damaging impact on the track caused by some deformations on the wheel. Proceedings of $22^{\text {nd }}$ International conference "Current problems in rail vehicles - PRORAIL 2015" II 22, 115-125 (2015) 